\title{
O PAPEL DO PROFESSOR NO ENSINO JURÍDICO: SABERES E FAZERES CONTEMPORÂNEOS
}

\author{
THE TEACHERS ROLE IN LEGAL EDUCATION: CONTEMPORARIES \\ KNOWLEDGE AND PRACTICES
}

\author{
${ }^{1}$ Patricia Veronica Nunes C Sobral de Souza
}

\section{RESUMO}

O presente artigo enfoca o papel do professor no ensino jurídico e privilegia as teorias que se debruçam sobre as relações pedagógicas desenvolvidas no contexto acadêmico dos cursos de direito. Trata-se de uma reflexão fundamentada na revisão de literatura especializada. $\mathrm{O}$ objetivo principal do estudo é o de compreender como professores e estudantes de direito conduzem e compreendem as relações entre ensinar e aprender, cotidianamente e, de que modo, o professor exerce o seu papel de mediador do conhecimento nesse interrelacionamento. A análise do processo de ensino-aprendizagem, compartilhando e construindo conhecimento, é, portanto, objeto desse estudo. As reflexões sobre o tema conduziram a inferências relativas à necessidade da elaboração conjunta (professores juristas e especialistas em Educação) de um planejamento de estratégias didático-metodológicas apropriadas à conquista da qualidade no processo ensino aprendizagem nos cursos de direito.

Palavras-chave: Aprendizagem, Educação, Ensino jurídico, Papel do professor

\begin{abstract}
This article focuses on the teacher's role in legal education and favors theories that focus on the pedagogical relationships developed in the context of academic law courses. It is a reasoned review of the literature on reflection. The main objective of the study is to understand how teachers and law students lead and understand the relationships between teaching and learning, every day, and that way, the teacher plays the role of mediator of knowledge in this inter-relationship. The analysis of the teaching-learning process, sharing and building knowledge, is therefore an object of the study. The reflections on the theme led us to inferences regarding the need for joint development (jurist teachers and experts in education) of planning didactic-methodological strategies appropriate to the achievement of quality in the teaching learning in law courses.
\end{abstract}

Keywords: Learning, Education, Legal education, Role of the teacher

\footnotetext{
${ }^{1}$ Doutoranda em Direito na Universidade Federal da Bahia - UFBA, Salvador - BA (Brasil). Professora da Universidade Tiradentes - UNIT, Aracaju - SE (Brasil). E-mail: patncss@ gmail.com
} 


\section{INTRODUÇÃO}

Integra a natureza humana a predisposição para ensinar. O homem sente prazer em repassar de geração a geração o conhecimento adquirido a partir de suas vivências e experiências, mesmo que de forma assistemática. O mesmo acontece com os artistas na composição de suas obras. A música e diversas outras manifestações das artes, por exemplo, sempre estiveram presentes ao longo de toda a história da civilização. O processo evolutivo é que vai impor a sistematização, o método, a técnica, o planejamento, as estratégias e o sistema de avaliação. Assim também tem acontecido no campo educacional, especificamente nas diversas conceituações e métodos de ensino, incluindo-se o âmbito da pesquisa científica que, continuadamente, busca aperfeiçoar-se.

Nesta ótica, o presente texto enfoca o papel do professor no ensino jurídico. Por isso, buscou-se observar, à luz das teorias, as relações pedagógicas desenvolvidas num contexto acadêmico. Isto é, mais precisamente a prática docente nos cursos de direito. O problema que se coloca neste artigo de revisão de literatura se constitui através da questão: o professor, ao exercer o seu papel de mediador do conhecimento no ensino superior, em um curso de direito, tem se utilizado de práticas metodológico-pedagógicas que conduzam os acadêmicos para um resultado de qualidade?

Para responder ao questionamento proposto, estabelece-se como objetivo principal compreender como professores e estudantes de direito conduzem e compreendem as relações entre ensinar e aprender, cotidianamente, e de que modo o professor exerce o seu papel de mediador do conhecimento nesse inter-relacionamento. O objeto de estudo desta reflexão é esse inter-relacionar-se que acontece no processo de ensino-aprendizagem, compartilhando e construindo conhecimento; e seu foco é a atividade docente que intervém e envolve o estudante no decorrer do processo pedagógico, verificando em que nível as práticas da docência superior estão voltadas para a aquisição de um ensino-aprendizagem de real qualidade, mais específico e ajustado aos objetivos do curso de direito. A presente argumentação se perfila à luz de um referencial teórico que, entre outros, envolve estudiosos, a exemplo de Alves (2006); Bernardina (2012); Colaço (2006); Menezes (2013); Mondrado (2006); Sobrinho (1997). A revisão de literatura especializada nos campos do Direito e da Educação foi o lastro metodológico adotado para tecer as considerações aqui desenvolvidas e sobre as quais se refletiu em busca de respostas aos nossos questionamentos. As estratégias perseguidas para a 
elaboração desta argumentação e reflexão nos impulsionaram as inferências a partir das quais foi possível organizar as considerações sobre o objeto de estudo.

Esse pendor para ensinar/aprender, natural do ser humano, percebe a dimensão de um indivíduo que consegue realizar alguma obra a partir da partilha construtora do conhecimento, fazendo uso de sua experiência, de sua prática cotidiana no desenvolvimento de ações educacionais. Ensinar e aprender são competências comuns ao professor, ao mestre, ao doutor e aos seus alunos, vez que todos dispõem de saberes e fazeres.

Enquanto as atividades educacionais se processam, concomitantemente, a sofisticação das ciências tem buscado o máximo de produção cognoscente e sua comprovação através de indícios, evidências e provas para que as teorias sejam consideradas verdadeiramente científicas. Particularmente, quanto ao processo ensino e aprendizagem, a história da educação segue ainda por caminhos tradicionais que põem o professor diante de discípulos e alunos, mas que continuam conferindo tão somente ao professor a posse dos saberes e fazeres, deixando o aluno fora do processo e sem considerar o que eles teriam como contribuição de suas vivências, leituras, observações e leitura de mundo.

Tendo em vista a formação da história da educação brasileira, devem ser levados em conta os momentos do processo educacional que merecem ser retomados e postos em debate. O Brasil tem sua história de ensino e de aprendizagem ligada à figura dos jesuítas da Companhia de Jesus, que aqui trataram de ensinar e de catequizar os indígenas, aculturando- os com o fito de atender aos objetivos e interesses da Corte portuguesa. Entretanto, esses habitantes naturais do Brasil tinham um sistema cultural e ensinavam aos seus filhos e netos, passando de geração em geração, os costumes e os hábitos daquelas tribos.

Depois dos jesuítas, o Brasil prossegue desenvolvendo a institucionalização do ensino considerado civilizado pelo colonizador que, naturalmente, priorizavam os moldes europeus. Assim, gradativamente, a cultura do indígena entrou, a partir da colonização portuguesa, em um processo de desvalorização e degradação.

Esses princípios da formação do sistema educacional brasileiro são, verdadeiramente, o germe que vai originar a fase em que o país se encontra, em pleno século XXI, na era da globalização e do avanço tecnológico e da comunicação.

São diversos os perfis que têm se delineado, ao longo desses séculos, desde o período da Colonização brasileira, e que descrevem aquele que é professor. Acontece que os avanços ocorridos ao longo de toda a história da educação brasileira impuseram os preceitos legais traduzidos em todo o conjunto de leis regedoras da área e, com isto, novas situações e 
interpretações do que é educar vão se fundindo no tempo e no espaço. A legislação acompanha o panorama sócio histórico nacional e evolui sempre em função da modernização do sistema educacional e da formação e qualificação docente. A esta altura do século XXI, o contex to é outro, mas, ainda assim, em reservas indígenas e povoados desassistidos socialmente, ainda existe a figura do professor leigo que alfabetiza as crianças valendo-se tão somente do pendor, da emoção e daquela predisposição natural para conduzir o indivíduo para o mundo da leitura e da escrita.

Dentro desse contexto, a história do ensino brasileiro, tanto das séries iniciais, quanto das seguintes, adentrando pelo Ensino Fundamental e Médio e, até mesmo, enveredando pelo Ensino Superior, tem seus altos e baixos e suas composições. Professores especialistas em Letras, por exemplo, em períodos carentes de pessoal habilitado pelas universidades ainda em etapa de fundação e desenvolvimento, já ministraram aulas de História, e até de Matemática, nas séries do Ensino Médio. Especificamente no âmbito do Ensino Superior, tempo houve (e ainda há) em que um médico se torna professor na área de Medicina e um advogado se faz professor de alguma disciplina do Direito, pois até a década de 90 não se pensava em um projeto pedagógico voltado aos cursos superiores. Sem que se adentre profundamente nos méritos de tal questão, sabe-se que eram e ainda são escolhidos aqueles caracterizados como bons médicos e os bons advogados para o preenchimento do quadro docente nas universidades. Anteriormente os critérios para a contratação docente eram os da indicação política e/ou e renome adquirido socialmente. Depois veio uma época na qual os candidatos a ocuparem as vagas de professor passavam por algum tipo de avaliação de desempenho feita também por professores dentro dessas mesmas características apontadas.

Entretanto, ser um bom médico e ser um bom advogado não são fatores suficientes para garantir a qualidade de um docente do Ensino Superior. Ser professor vai além da crença de que alguém, tão somente por conhecer determinado campo do conhecimento humano (por trabalhar nele) esteja apto para exercer o magistério. A pedagogia é uma ciência e, como tal, precisa de assim ser compreendida e assumida. Juntaram-se a legislação e o conhecimento científico no sentido de conferir à docência o status que merece e sem o qual não se desenvolve o processo ensino e aprendizagem, quer nas séries iniciais, especialmente, quer nas séries subsequentes e no Ensino Superior - afinal, é neste que são formados os professores da era presente e que precisam atender às exigências da sociedade atual. Inclusive e especificamente, a crítica ao ensino nos cursos de direito recai sobre a necessidade da 
correta aplicação das técnicas didático-metodológicas, do planejamento de um projeto político-pedagógico, dependentes diretamente da competência dos profissionais da Educação e da participação do professor $\times$ aluno sobre as quais se forma a expectativa de que devem exercitar a reflexão crítica sobre a ciência do Direito.

\section{DESENVOLVIMENTO}

Responder à complexa questão que investiga se o professor, ao exercer o seu papel de mediador do conhecimento no ensino superior, em um curso de direito, tem se utilizado de práticas metodológico-pedagógicas que conduzam os acadêmicos para um resultado de qualidade tem direto relacionamento com a condução segura dos graduandos pelos caminhos do ensino e aprendizagem, exigindo-se explicitar a relação que esse e outros cursos têm mantido, historicamente, com a perspectiva didático-pedagógica.

Médicos têm sido formados para a prática da Medicina nos hospitais e em outras casas de saúde, entretanto, são muitos entre esses médicos que vêm, ao longo das décadas da nossa história educacional, ensinando nos cursos de Medicina. O mesmo vale para cursos no âmbito das ciências exatas ou, como é o presente caso, o do Direito. Professores de inúmeras disciplinas que fazem parte do currículo do curso de Direito entram para o magistério superior sem terem recebido a formação específica para as questões atinentes ao planejamento pedagógico, à didática e à pedagogia. Em detrimento de muitos desses profissionais se posicionarem (ou serem posicionados) academicamente e socialmente como excelentes médicos, advogados ou outro tipo qualquer de profissional, eles têm enfrentado as salas de aula sem que dominem os meandros do mecanismo educacional e das entranhas da pedagogia, a exemplo das técnicas, estratégias de ensino, do planejamento e da avaliação do ensino e da aprendizagem.

Dessa situação tradicional e tradicionalista no ensino jurídico, por exemplo, advêm muitos problemas: exagero de disciplina, falta de entrosamento/comunicação alunoprofessor-aluno, falhas no rendimento da aprendizagem, abordagens inadequadas, técnicas desnorteadas, ausência de planejamento ou planejamento equivocado, estratégias mal traçadas e elaboradas sem que seja esboçado um quadro de objetivos claros e bem delineados, reclamações diversas dos alunos, avaliações injustas, desconhecimento da legislação educacional e das novas teorias educacionais, entre outros. Metaforizando, se diria tratar-se de 
um profissional da medicina que prescreve medicamentos sem que tenha examinado e avaliado o seu paciente. Ou seria o juiz a condenar um réu sem que tomasse conhecimento dos autos do processo. Já é tempo de entender que, embora em sua origem a palavra latina "aluno" signifique "sem luz", a oferta a eles, hoje, de conteúdo enciclopédico, de modo indiferente ou inumano, sem macetes pedagógicos, é prova de uma visão de ensino ainda arcaica e descuidada, como se depreende da leitura acurada do que se segue:

Remanesce à Antiguidade a preocupação com o ensino, mormente o jurídico. Os sofistas, que se consideravam donos do saber, tinham um viés voltado para o alcance simplesmente dos seus objetivos, ou seja, vislumbravam uma educação volvida para o desenvolvimento puramente individual ou pessoal, como fazem os atuais advogados, cuja cultura é vencer os adversários nos processos, a qualquer custo. Ao passo que o filósofo Sócrates, opositor ferrenho dos sofistas, visava um educar diferenciado, com base na dialética, focado na formação humana, e voltado para o bem da "Pólis" em si mesma (SOBRAL DE SOUZA, 2013, p. 577).

Colaço (2006, p. 15) também remonta ao passado da educação brasileira, para relembrar que:
O ensino do Direito no Brasil herdou o caráter conservador da Universidade de Coimbra, com suas aulas-conferência, ensino dogmático, mentalidade ortodoxa do corpo docente e discente, a serviço da manutenção da ordem estabelecida e transplantada da ex-metrópole, oportunizando aos profissionais por ele formados o prestígio local e ascensão social.

Um quadro de ensino e aprendizagem com este desenho não tem o professor como mediador de aprendizagem, mas tão somente um professor nos moldes tradicionais e de comportamento altivo, que dita, que ordena, que exige, e cuja prática tem, em geral, conduzido a resultados educacionais de pouca ou nenhuma qualidade.

Outras consequências podem também ser apontadas a partir das estatísticas que apresentam as notas oficiais de desempenho dos cursos em avaliações realizadas por setores competentes do MEC, do próprio desempenho dos graduandos quando submetidos ao temido Exame da OAB; e, quanto, em geral, ao desempenho na profissão dentro dos escritórios de advocacia, na redação de documentos e pareceres; ou ainda, também, tornando-se professores de disciplinas constantes do currículo dos cursos de Direito, contribuindo para a manutenção de um ensino crítico e desvinculado da realidade.

São inúmeras as teorias que analisam as relações de ensino e aprendizagem no ensino jurídico, além de examinarem a prática pedagógica e as relações professor $\times$ aluno $\times$ professor. Para ilustrar esse relacionamento em sala de aula, tome-se emprestada a palavra de Menezes (2013, p. 84): 


\begin{abstract}
Há muito tempo, os educadores vinham utilizando os métodos clássicos de ensino, e realmente acreditavam que estavam ensinando, porém, o que se tinha era imposição da matéria e consequentemente um aprendizado falho, porque não dizer deficiente, pois os alunos ficavam de fora do processo de aprendizagem. $\mathrm{O}$ professor era visto como autoridade máxima, não sendo permitido fazer interferência de modo de algum no seu modo de transmitir a sua disciplina.
\end{abstract}

Atualmente, e por força da Lei que rege a educação nacional, a (LDB) Lei de Diretrizes e Base $n^{\circ}$ 9.394/96 e mais um conjunto de documentos norteadores, a exigência da formação para o ensino se ampliou e criou um caráter de obrigatoriedade. Dessa forma, nota- se já essa preocupação e um redirecionamento que busca o aperfeiçoamento de profissionais que exercem suas atividades nos locais de fato e de direito, como também no papel de professores em universidades. Essa mudança agrega valor aos cursos e cria obrigações voltadas para um processo de ensino e aprendizagem pautado na ciência da Educação.

Esta reflexão ilumina o pensamento daqueles que buscam compreender como professores e estudantes de Direito conduzem as relações entre ensinar e aprender, cotidianamente, e de que modo o professor exerce o seu papel de mediador do conhecimento nesse inter-relacionamento. A relação ensinar/aprender não pode ser, a esta altura da evolução socioeducacional e, muito principalmente, considerando-se o avanço das tecnologias, vista como no passado em que o professor tinha desde a primeira à última palavra dentro da sala de aula, era o conhecedor do conteúdo, uma sumidade sobre cuja fala nada se poderia objetar. Era a própria figura do detentor único do saber, não devendo ser questionada em hipótese alguma - situação que nubla o pensamento científico, que limita o raciocínio e que, em lugar de formar, deforma.

Estudos de Copetti e Morais (2007) cuidam de abordar aspectos do ensino do Direito como condição de possibilidade para a concretização de um projeto de felicidade presente no texto da Constituição Federal. Esses aspectos têm estreita relação com a felicidade e a formação intelectual e a mesma noção de felicidade no ensino jurídico, entre outros. Na retrospectiva que empreendem, os dois estudiosos referem-se ao conceito grego de felicidade e pontuam que o projeto comunitário grego, como também desejos que se voltavam à realização de "projetos individuais dos cidadãos helênicos que compunham a arquitetura de suas felicidades, só se tornaram possíveis graças a um processo civilizatório baseado na cultura e na educação" (COPETTI e MORAIS, 2007, p. 13).

Quanto aos aspectos da felicidade nos campos político e jurídico, esses estudiosos evidenciam que, especificamente no campo político ou da política propriamente, "não muito 
distante está a situação de tal temática no campo jurídico", quase que totalmente esquecida pelos juristas:

[...] mais preocupados com questões dogmáticas, com cotidianidades processuais ou com sucessos profissionais no âmbito individual, não menos olvidadas têm sido as múltiplas questões que compõem a complexidade do que se chama felicidade, quando se fala em termos de ensino jurídico. (COPETTI e MORAIS, 2007, p. 15).

Fato é que firme está o entrelaçamento entre a Constituição e a educação no conteúdo material da educação no cenário constitucional brasileiro pós-88, conforme previsto no projeto do Estado de Direito pela inclusão dos conteúdos das liberdades, igualdades e solidariedades, o que ilumina a atuação estatal em suas vertentes legislativa, executiva e jurisdicional, "bem como supõe garantias, prestações ou transformações" (COPETTI e MORAIS, 2007, p. 25).

O objeto de estudo ora exposto e em análise pretende ampliar o debate sobre esse interrelacionar-se em situações de sala de aula, enquanto se ensina e se aprende pela interação, pela participação ativa, pela abordagem de temas atuais, pelo desenvolvimento do senso crítico e pela noção do que é ciência, método científico e produção de conhecimento dentro de uma área específica. Sendo assim, compartilha-se e erige-se um saber sobre o qual repousa a qualidade advinda da atividade docente que intervém e envolve o estudante no decorrer do processo pedagógico.

A influência do pensamento "paulofreiriano" percorre quase toda a produção sobre o processo ensino aprendizagem, no Brasil, mas outros países têm levado muito a sério a proposta do mestre educador de que "ninguém educa ninguém; ninguém se educa sozinho, os homens se educam em comunhão" (FREIRE, 1996, p.89).

Profundamente entremeado e acorde com o pensamento educacional é o estudo de Sobrinho (1997) sobre a metodologia do ensino jurídico e a avaliação em Direito. O estudioso se debruça sobre questões que se estendem desde o perfil do professor até as concepções de uma universidade, por vezes irreal ou mesmo surreal que, durante muito tempo, "conseguiu manter a imagem romântica de centro destinado à meditação científica", um ambiente em que os professores estavam despojados de questões materiais da vida comum e que, "por isto mesmo, estavam interessados no conhecimento pelo conhecimento, ou seja, não tinham o escopo do lucro permeando suas pesquisas" (SOBRINHO, 1997, p, 129). 
Com respeito direto ao currículo do curso de Direito, Sobrinho (p. 41) destaca um passado de críticas que apontavam as deficiências e as características de um discurso estereotipado, repetidos ad nauseam até que veio a Resolução n. 3, de 1972, "do extinto Conselho Federal de Educação, que se constituiu a direção normativa do ensino jurídico até o ano de 1994" em cujo artigo $1^{\circ}$. estipula-se o currículo mínimo estruturado em matérias Básicas e Profissionais.

Talvez fosse bom considerar a possiblidade de (des)construção do ensino jurídico como vinha sendo processado a longas e ininterruptas décadas, aquele clima de augusta solenidade, aquele contexto de magister dixit e aquela linguagem muitas vezes inentendível, dita como uma oração que se memoriza e se repete automaticamente, como reafirma Bittar (2006):

\begin{abstract}
O modelo vigente é herdado desta clássica forma de compreender, de modo liberal e positivista, a realidade do Direito. Uma aula de Direito, no século XIX, sobretudo nas academias mais tradicionais e mais antigas do Brasil (São Paulo e Olinda), está revestida de um simbolismo sem par. Quase um ritual se segue até que a aula se inicie, ou seja, até quando o lente catedrático comece a proferir sua lectio. A aula é uma proposta de leitura in verbis do texto da legislação em vigor, e reflete no máximo a capacidade de interpretação literal da textualidade legal. A letra da lei parece tão sagrada e inviolável quanto a letra das Sagradas Escrituras; não pode ser alterada, violada e deve ser capturada em seu sentido mais originário possível. Eis o princípio da hermenêutica jurídica, a partir da hermenêutica sagrada. O Livro Sagrado? A Bíblia do jurista? O Código, ou o compêndio de legislação (BITTAR, 2006, p. 5).
\end{abstract}

Esse tipo de pedagogia pertenceu ao passado e, de alguma maneira, diga-se que tenha apresentado resultados positivos. Sim, grandes estudiosos e mestres do Direito têm seus nomes aureolados de honra, glória e produção de obras até hoje respeitadas e referências na área jurídica, a exemplo de Augusto Teixeira de Freitas, considerado o Jurisconsulto das Américas, o Maior Codificador Brasileiro, filho do Barão de Itaparica, o mais importante jurista brasileiro do séc. XIX; e ainda Carneiro Ribeiro, antigo professor de Ruy Barbosa no Liceu Baiano. Entretanto, o tempora, o mores, a humanidade vive uma fase de um processo de modernização jamais pensado, como é o caso do avanço das tecnologias e mais uma efervescência diferenciada trazida por novíssimos contornos da globalização; da amplitude com que a comunicação e a informação abraçam a todos. Nesse contexto novo, descobre-se que:

\footnotetext{
Parece ser compartilhada por muitos a certeza de que o modelo tradicional de ensino jurídico, baseado na centralidade da figura do professor, no poder do saber, na lógica epistemológica cartesiana, na autoridade docente e na exegese da norma, por meio de intérpretes/doutrinadores sem qualquer formação humanística, não foi e não é capaz de atender às exigências de um mundo cada vez mais complexo e plural (BUSSINGUER, 2013, p. 55-56).
} 
Reportando-se à (des)construção do ensino jurídico, Boldt e Khroling (2013, p. 31) enfatizam o fascínio exercido pelo Direito Penal e pelos frágeis liames que podem conduzir estudantes de Direito pelas "situações emocionantes, com narrativas permeadas de violência e crueldade, capazes de expor a curiosidade humana pela tragédia”. Assim, exempli gratia,

\begin{abstract}
A elaboração de uma atividade interdisciplinar na disciplina Direito Processual Penal III e a assunção da perspectiva transdisciplinar no ensino das ciências criminais tem possibilitado a abertura de espaços entre diferentes tempos do conhecimento, entrelaçando, por exemplo, o processo penal, a criminologia e a filosofia. (BOLDT e KHROLING, 2013, p. 33).
\end{abstract}

O desacerto didático-pedagógico dos Cursos de Direito alcançou um ponto em que o ensino jurídico, no Brasil, tornou-se "estigmatizado por duas características que dificultam a formação de profissionais capacitados para o atendimento das necessidades do mercado de trabalho e conscientes da função social do Direito" (BERNARDINA, 2013, p. 1).

As metodologias de ensino têm tomado de exemplo ensinamentos lastrados em uma compreensão da dimensão dialógica do processo educacional e, ainda aos aspectos que envolvem a criação, o questionamento, a análise e a produção do conhecimento que se originam da relação professor-aluno-professor e todo o corpo educacional em macro contextos. Nas palavras de Stangherlim (2013, p. 10):

Freire sempre enfatizou a importância da ética e do compromisso político como dimensões indissociáveis do ato de educar. Desse modo, compreende- se de trazer para o campo acadêmico a reflexão e a análise de uma metodologia de ensino, com base no legado freiriano e de sua pedagogia do oprimido, parece ser bastante oportuno, considerando os pressupostos de sua teoria e, para além disso, tendo em vista a conjuntura em que se apresenta a educação brasileira dos últimos anos.

Tanto preocupa essa questão da metodologia do ensino do Direito que foi criada a Associação Latino Americana de Metodologia do Ensino do Direito (ALMED), fundada por um professor de Direito da Universidade Federal de Santa Catarina, entidade que funcionou de 1980 a 2000. Nela, fazia-se uma proposta diferenciada, baseada no amor e no afeto, buscando novas formas e criticando o método tradicional do ensino jurídico, mas "não se conseguiu a transformação do professor em mestre" (MONDARDO, 2006).

A reflexão proposta aqui busca sobressair à insistência sobre esse foco nitidamente irrecorrível e inarredável, tendo em vista os compromissos e produtos da investigação científica de profissionais que analisam e testam todas as etapas do processo ensino e aprendizagem, trazendo à luz das mais importantes teorias o resultado que interessa ao social 
e não apenas a uma parte da sociedade com conceitos falsificados do que seria um ensino de qualidade.

Urge, pois, que, no caso do ensino jurídico, cada professor se questione sobre que rotas têm trilhado com a prática exercida cotidianamente: se pelas rotas dos mares da colonização, junto com os colonizadores e contribuindo para a perpetuação da atitude submissa aos que se posicionam como líderes; ou se pelas águas mais recentes do avanço da civilização em pesquisas de comprovada importância, tanto nacionais quanto internacionais, e em resultados traduzidos nas estatísticas.

Tomando de empréstimo a epígrafe da obra Estudos sobre Ensino Jurídico (BITTAR, 2006): "Homines dun dicent discunt" ("Ensinando, os homens aprendem”), de Sêneca, em Epistulae ad Lucilium, (I,7,8) o pensamento deste estudo se encaminha para as questões da prática docente. Praticando no dia a dia da sala de aula, o professor sente em seu íntimo que, por exemplo, a aula que ministra hoje lhe parece incomparavelmente melhor do que essa mesma aula ministrada ontem, ou mesmo na aula anterior, de há poucos minutos correspondentes ao intervalo entre uma aula e outra. Assim, docentes, mesmo que silenciem, têm a certeza de estarem sempre se renovando e aperfeiçoando sua prática, renovando seus saberes e aperfeiçoando seus fazeres.

Entretanto, essa prática não é um milagre, a não ser que se fale metaforicamente de um milagre educacional, da técnica, do método, da didática e da pedagogia. O milagre educacional se funda nos princípios da Didática e da Pedagogia acompanhados da produção de conhecimento, da interação ininterrupta com os estudantes, do debate, do exercício consciente e da avaliação que testemunha os resultados considerados de qualidade. Claro está que esses resultados, fora desses princípios regedores da ação docente, só produzem um ensino frustrado, de péssima qualidade e que lança, na sociedade e no mundo do trabalho, profissionais desqualificados, despreparados para o exercício da profissão que escolheram.

O universo educacional, seja público ou privado, carece mais e mais de inovação em educação, mais precisamente no foco deste estudo, na educação superior, com professores comprometidos e detentores de conhecimentos pedagógicos. Esta carência tem minorado com os cursos de formação para docentes oferecidos pelas instituições públicas e particulares de Ensino Superior e a exigência destas instituições de professores mestres e doutores.

Seguindo essa ótica, Colaço (2006), trata do tema em seus estudos, propondo a máxima: ensinar direito o Direito. Mas o que precisamente seria isso? 
Evidente está na argumentação que se formula neste artigo que ensinar direito o Direito seria uma transformação desse ensino que, como lembraram estudiosos citados no início do texto, era um exercício de autoridade e indiferença com relação aos acadêmicos, tratados como recipientes do conhecimento demonstrado orgulhosamente e até pedantemente pelas suas lentes. Ensinar “direito o Direito" tem, portanto, íntima relação com a ciência da Educação e com seus postulados, teorias, práticas e experimentos, num constante fazer-avaliar-refazer e assim por diante. Por isto mesmo os estudos reunidos por Colaço propõem a capacitação docente no contexto das políticas para a educação superior, a consideração de aspectos da metodologia do ensino do Direito, a docência e a interdisciplinaridade como desafio pedagógico, a aprendizagem no Curso de Direito fundamentada na práxis da cidadania inspirada em pensadores como Vygotsky, Paulo Freire e Edgar Morin (especialistas em Educação), a educação para os direitos humanos, o ensino jurídico por meio da extensão universitária, as alternativas pedagógicas para esse tipo de ensino, a discussão enquanto técnica de ensino do Direito, que efetiva o construtivismo no processo ensino-aprendizagem, e a conscientização para a transformação pelas vias da educação ambiental.

Naturalmente, para além desses aspectos contemplados, há uma gama de abordagens próprias do contexto educacional e, para apreendê-los será necessário pesquisar, produzir conhecimento e exercitar até que, tanto os docentes dos cursos de Direito, quanto os de outros cursos superiores se conscientizem que ensinar, além de pressupor talento e dedicação, é também uma arte e uma ciência. Em virtude disto, Colaço frisa, na apresentação da obra, que, porventura pudesse ser considerado um trabalho "presunçoso", mas adiantou: "nós, professores, devemos ter a consciência de que precisamos parar e refletir sobre as nossas práticas profissionais cotidianas e voltar continuamente a estudar para aprender a ensinar" (COLAÇO, 2006, p. 8).

Especificamente sobre o ensino do Direito e a capacitação docente, Colaço ainda assevera na condição de fator preponderante nesse contexto "a heterogeneidade dos profissionais da educação do Direito, em cujo meio aparecem o professor profissional e o profissional professor", além disto, pontua “que nem sempre titulação é garantia de competência pedagógica". De forma mais contundente, a autora denuncia que o "ensino do Direito tem sido marcado pelo amadorismo, que causa muitos danos a alunos e professores" (COLAÇO, 2006, p. 13-14). 
A interdisciplinaridade é uma espécie de ciranda das áreas de conhecimento, um entrelaçamento, um compartilhamento, um dar-se as mãos de forma cooperativa, uma produção de amplos saberes encaminhadores de novos e renovados fazeres. Dessa forma, cada área dar-se-ia às outras e das outras também receberia. É dizer que um diálogo seria formado e dele nasceriam contribuições que gerariam mais e mais conhecimentos.

A proposta da interdisciplinaridade, entretanto, tem sido vista como difícil, inclusive pelos educadores, acostumados à compartimentalização do saber. Essa dificuldade vem, exatamente, de toda uma história da formação do processo educacional brasileiro em que cada área se isola e se coloca em um pedestal inacessível; ademais, seus membros, a depender de concepções e representatividades, consideram suas áreas como mais importantes, necessárias, indispensáveis e nobres - afastando-se assim as partes constitutivas do saber humano. É como se um cristal fosse fragmentado e as suas peças não pudessem mais se unir. Todas as áreas necessitam do conhecimento linguístico, pois com ele se expressam e produzem mais conhecimentos, não necessariamente pelo excesso de erudição, mas pela objetividade, pela coerência, pela clareza e cientificidade explícita.

A linguagem, por sua vez, precisa conhecer noções, pelo menos básicas, de outros campos desses saberes humanos, pois assim conseguirá expressar-se com mais propriedade e profundidade. Na opinião de Alves (2006), o maior obstáculo para que aconteça esse congraçamento entre áreas e disciplinas é a formação das matrizes curriculares dos cursos jurídicos. O desenho dessas matrizes tem cerceado a integração, não apresenta áreas de concentração proporcionadoras da formação da identidade do curso, "dificultando a formação integral e a concepção de totalidade necessária à formação interdisciplinar”.

\section{CONSIDERAÇÕES FINAIS}

Assim como é natural ao ser humano o desejo de aprender e de ensinar, a mesma naturalidade existe para a crítica, o palpite e a avaliação. A sociedade se manifesta tentando ensinar a ensinar quando ainda não aprendeu o suficiente, isto é, sem o devido conhecimento de causa. Essa mesma sociedade estipula modelos, elabora conceitos e, ainda, também legisla em causa própria. É essa sociedade que cria heróis, ícones e representatividades. Entre essas convenções, a sociedade há muito entende que tal ou qual graduação ou titulação tem mais ou menos valor que outra(s). Historicamente, no Brasil, convencionou-se que os cursos de 
Direito e de Medicina são os mais importantes, os que oferecem retorno financeiro e os que conferem mais status social. Deve-se a um decreto assinado por Dom Pedro I, em 1825, o tratamento de "doutor" dado aos bacharéis em Direito. Paralelamente, a mesma valorização e tratamento não foram dispensados aos professores que amalgamam não apenas os doutores advogados, mas todos os outros profissionais.

A Educação, relegada ao último plano, entretanto, seguiu sua rota de dedicação, de teorização e de prática vista e revista em busca de cumprir o objetivo de formar integralmente os sujeitos sob os seus cuidados. Anos de descaso imposto à Educação geraram os mais diversos problemas, pois, em lugar de respeitar o educador, seus saberes e fazeres, a sociedade tem demonstrado essa atitude de assunção das responsabilidades educacionais. Os resultados dessa forma de pensar têm criado empecilhos de toda a sorte e em todas as faixas do ensino brasileiro. Mas, nada dura indefinidamente e, felizmente, tem-se notado o despertar do interesse pelos estudos e pesquisas no âmbito da educação. Isto ocorre graças a ações de políticas públicas que tentam resgatar a Educação e valorizar os seus profissionais.

O avanço e aperfeiçoamento da legislação educacional e documentos norteadores como os PCNs (Parâmetros curriculares nacionais) contribuem decisivamente para essa mudança de mentalidade, pois "foram elaborados para difundir os princípios da reforma curricular e orientar os professores na busca de novas abordagens e metodologias". O currículo é, portanto, um constructo não finalizado ou engessado do conhecimento, o qual pode - e deve - ser visto como positivo no que tange a direcionar a prática docente. Enfim, o que se observa de melhor é esse redirecionamento e essa contemplação com os preceitos de uma das mais importantes ciências, a Pedagogia. A partir dessa atitude e mudança de comportamento se observa o reposicionamento de professores que reconhecem o fracasso de seus alunos e, assim, começam a repensar suas práticas docentes.

O Curso de Direito, de nobre história e renome, em detrimento de ainda gozar de prestígio, já não consegue esconder daquela mesma sociedade o empobrecimento do desempenho de seus graduados, o insucesso na avaliação da $\mathrm{OAB}$ e na prática profissional em qualquer dos ramos da advocacia ou do magistério em Direito.

A experiência do professor é, sem dúvida, importante para tornar a vivência jurídica mais tangível ao alunado, mas não substitui o conhecimento pedagógico - podendo se tornar apenas meros relatos de casos curiosos ou contação de história, se não preparados à luz de objetivos pedagógicos. Estes fazem toda a diferença no processo de ensino e aprendizagem, 
sejam eles oriundos de cursos de curta duração frequentes, seja de especializações, mestrado ou doutorado.

O problema que se colocou neste artigo de revisão de literatura buscou responder à questão relativa a se o professor, ao exercer o seu papel de mediador do conhecimento no ensino superior, em um curso de direito, tem se utilizado de práticas metodológico- pedagógicas que conduzam os acadêmicos para um resultado de qualidade/melhoria. A resposta ainda é incipiente. Por tal razão, necessário se faz continuar firmemente na busca de métodos, técnicas e estratégias que ofereçam amor, afeto, compartilhamento, interação e atividades promotoras da interdisciplinaridade para o ensino jurídico. Para esse esforço lograr êxito, deve haver a convicção de que a equipe gestora do planejamento estratégico didático- metodológico precisa envolver profissionais do Direito e da Educação. Deve-se respeitar o passado, pois o valor dele é inegável, mas, com urgência, os olhos e os ouvidos devem estar abertos para a nova realidade social e, especialmente, da obrigação constitucional de oferecer ensino e aprendizagem de qualidade, para formar integralmente e conduzir o sujeito à realização pessoal e profissional, garantindo-lhe a inserção no mundo do trabalho.

\section{REFERÊNCIAS}

ALVES, Elisete Lanzoni. A docência e a interdisciplinaridade: Um desafio pedagógico. In COLAÇO, Thais Luzia (org.). Aprendendo a ensinar direito O Direito. Florianópolis: OAB/SC Editora, 2006. 344 p.

ARAÚJO, Edvaldo Lopes de Araújo; PINTO, Tainá de Araújo. Teoria Geral do Direito Civil. UniverCidade: Súmulas de Aulas, 2011. Disponível em: http://www.passeidireto. com/arquivo/1923548/historia-do-direito/34. Acesso em 21 ago 2014.

BERNARDINA, Alexandre Dalla. A utilização de decisões judiciais como estratégia de ensino na disciplina de Responsabilidade Civil. In MIGUEL, Paula Castello; OLIVEIRA, Juliana Ferrari de. Estratégias pedagógicas inovadoras no ensino jurídico. Rio de Janeiro: Lúmen Júris, 2012. 211p.

BITTAR, Eduardo C. B. Estudos sobre ensino jurídico: pesquisa, metodologia, diálogo e cidadania. - 2. ed. Rev., modificada, atual. e ampl. - São Paulo: Atlas, 2006. 246 p.

BOLDT, Raphael e KHROLING, Aloísio. O processo interdisciplinar: (des)construindo o ensino das ciências criminais. In MIGUEL, Paula Castello; OLIVEIRA, Juliana Ferrari de. Estratégias pedagógicas inovadoras no ensino jurídico. Rio de Janeiro: Lúmen Júris, 2012. $211 \mathrm{p}$. 
BUSSINGUER, Elda Coelho de Azevedo. Ensino jurídico e aprendizagem significativa: uma tentativa de compreensão da tragédia, do direito e da justiça a partir de uma abordagem fenomenológica. In MIGUEL, Paula Castello; OLIVEIRA, Juliana Ferrari de. Estratégias pedagógicas inovadoras no ensino jurídico. Rio de Janeiro: Lúmen Júris, 2012. 211p.

BRASIL. Ministério da Educação. Parâmetros Curriculares Nacionais. Secretaria de Educação Básica: Brasília (DF), 2006. Disponível em: http://provabrasil.inep.gov.br/ parametros-curriculares-nacionais. Acesso em 23 ago 2014.

COLAÇO, Thais Luzia. Ensino do direito e capacitação docente. In COLAÇO, Thais Luzia (org.). Aprendendo a ensinar direito O Direito. - Florianópolis: OAB/SC Editora, 2006. 344 p.

COPETTI, André e MORAIS, José Luiz Bolzan de. Ensino do Direito como condição para a concretização de um projeto de felicidade presente na Constituição Federal brasileira. In SANTOS, André Leonardo Copetti. MORAIS, José Luiz Bolzan de. O ensino jurídico e a formação do bacharel em Direito: diretrizes político-pedagógicas do curso de Direito da UNISINOS. - Porto Alegre: Livraria do Advogado Editora, 2007. 135 p.

FREIRE, Paulo. Pedagogia do Oprimido. 29 ed., Rio de Janeiro: Editora Paz e Terra. 1996. 89p.

LEONTIEV. A. O Desenvolvimento do Psiquismo. Lisboa: Horizonte Universitário, 1978. $298 \mathrm{p}$.

MENEZES, Adriana Maria Celestino. Ensino jurídico no Brasil - Uma questão a ser solucionada. In PESSOA, Flávia Moreira Guimarães (org.). Reflexões sobre a Docência Jurídica. Série Estudos de metodologia. Volume 1 - Aracaju: Evocati, 2013. 654 p.

MONDARDO, Dilsa. Metodologia do ensino do Direito: memórias de um cronópio. In COLAÇO, Thais Luzia (org.). Aprendendo a ensinar direito O Direito. Florianópolis: OAB/SC Editora, 2006. 344 p.

SOBRAL DE SOUZA, Patrícia Verônica Nunes Carvalho. O Ensino jurídico: Um desafio a ser enfrentado pelos docentes? In PESSOA, Flávia Moreira Guimarães (org.). Reflexões sobre a Docência Jurídica. Série Estudos de metodologia. Volume 1 - Aracaju: Evocati, 2013. $654 \mathrm{p}$.

SOBRINHO, José Wilson Ferreira. Metodologia do ensino jurídico e a avaliação em direito. Porto Alegre: Sergio Antonio Fabris Editor, 1997. 175p.

STANGHERLIM, Roberta. Metodologia de ensino na concepção de educação de Paulo Freire. In BAPTISTA, Ana Maria Haddad; NOBREGA, Maria Luiza Sardinha de; TODARO, Mônica (orgs.). Metodologias de Ensino: entre reflexão e a pesquisa (Pedagogia de A a Z; vol. 10). Jundiaí, Paco Editorial: 2013. 192 p. 